\title{
AUTHOR INDEX (2002)
}

Abd-Allah, N.N., see Mohery, M.

Abd-Allah, N.N., Study of forwardbackward shower particle and slow proton production from the interactions of ${ }^{7} \mathrm{Li}$ with emulsion nuclei at $3 \mathrm{~A} \mathrm{GeV/c}$

Abdel-Fattah, O.S., see El-Nohy, N.A.

Abdel-Monem, A.M., see El-Nohy, N.A.

Abdulmomen, M.A., see Ahmad, I. Adam, R.M., see Mabuza, B.R.

Ahmad, I., Abdulmomen, M.A. \& Alvi, M.A., Eikonal description of ${ }^{12} \mathrm{C}-{ }^{12} \mathrm{C}$ elastic scattering in terms of phenomenological effective NN potential

Ahmad, N., see Bari, W.

Ahmad, S., see Bari, W.

Alvi, M.A., see Ahmad, I.

Amin, M.M., see Doma, S.B.

Anagnostatos, G.S., see Avrigeanu, M.

Anagnostatos, G.S., see Gridnev, K.A.

Antonov, A.N., see Avrigeanu, M.

Avrigeanu V., see Avrigeanu, M.

Avrigeanu, M., Anagnostatos, G.S., Antonov, A.N. \& Avrigeanu, V., Elastic scattering as a test of density distributions in ${ }^{6} \mathrm{He}$ and ${ }^{8} \mathrm{He}$

Bakker, B.L.G., see Mabuza, B.R.

Banerjee, P., Krishan, K., Bhattacharya, S. \& Bhattacharya, C., Fusion of light proton-rich exotic nuclei at near-barrier energies

Bari, W., Ahmad, N., Khan, M.M., Ahmad, S., Zafar, M. \& Irfan, M., Intermittency in $4.5 \mathrm{~A}$ and $14.5 \mathrm{~A}$ $\mathrm{GeV} / \mathrm{c}{ }^{28}$ Si-nucleus interactions

Berezhnoy, Yu.A. \& Mikhailyuk, V.P., Elastic ${ }^{12} \mathrm{C}-{ }^{12} \mathrm{C}$ scattering at intermediate energies

Bhardwaj, H.D., see Gupta, S.

Bhattacharya, C., see Banerjee, P.

Bhattacharya, S., see Banerjee, P.

Bhattacharyya, S., see De, B.

Bhattacharyya, S., see De, B.

Boukahil, A., see Zettili, N.
E11(2) 161

E11(2) 105

E11(5) 437

E11(5) 437

E11(6) 519

E11(1) 35

E11(6) 519

E11(2) 131

E11(2) 131

E11(6) 519

E11(5) 455

E11(3) 249

E11(5) 359

E11(3) 249

E11(3) 249

E11(3) 249

E11(1) 35

E11(6) 491

E11(2) 131

E11(4) 281

E11(1) 45

E11(6) 491

E11(6) 491

E11(4) 289

E11(5) 387

E11(3) 231
Cha, M.H., see Kim, Y.J.

Chadderton, L.T., see Kun, S.Yu.

E11(3) 211

E11(4) 273

De, B., Bhattacharyya, S. \& Guptaroy, P., Antideuteron production and the physics of coalescence: Implications of a new approach

E11(5) 387

De, B., Bhattacharyya, S. \& Guptaroy, P., Composite particle formation in $\mathrm{Au}+\mathrm{Au}$ reactions at 11.6A GeV/c: Towards a new approach

de Freitas Pacheco, J.A., see Marranghello, G.F.

Dias, H., see Leite, T.N.

Dillig M., see Marranghello, G.F.

Doma, S.B. \& Amin, M.M., The single particle Schrödinger fluid and moments of inertia of the nuclei ${ }^{24} \mathrm{Mg},{ }^{25} \mathrm{Al},{ }^{27} \mathrm{Al},{ }^{183} \mathrm{~W}$ and ${ }^{238} \mathrm{Pu}$

E11(5) 455

Dong, S. \& Dong, S.-H., A realization of dynamic group for an electron in a uniform magnetic field

E11(4) 265

Dong, S., see Dong, S.-H.

Dong, S.-H. \& Ma, Z.-Q., Algebraic approach to the pseudoharmonic oscillator in $2 D$

Dong, S.-H., Gu, X.-Y., Ma, Z.-Q. \& Dong, S., Exact solutions of the Dirac equation with a Coulomb plus scalar potential in $2+1$ dimensions

Dong, S.-H., see Dong, S.

Dong, S.-H., see Gu, X.-Y.

El-Akkad, F.A., see El-Nohy, N.A. El-Nohy, N.A., El-Akkad, F.A., Abdel-Monem, A.M. \& AbdelFattah, O.S., Double folding analysis of ${ }^{6} \mathrm{Li}$ scattering by ${ }^{12} \mathrm{C},{ }^{40} \mathrm{Ca},{ }^{90} \mathrm{Zr}$ and ${ }^{208} \mathrm{~Pb}$

El-Nohy, N., Shell model calculations of ${ }^{3} \mathrm{~T},{ }^{5} \mathrm{He}$ and ${ }^{6} \mathrm{Li}$ nuclei

Faessler, A., see Kukulin, V.I.

Farag, M.Y.H. \& Hassan, M.Y.M., Relativistic optical model for proton-nucleus elastic scattering
E11(5) 437

E11(1) 67

E11(1) 1

E11(6) 483

E11(4) 265

E11(4) 335

E11(5) 437

E11(5) 425 
Gao, C.-Y. \& Zhang, Q.-R., Relativistic mean field theoretical foundation of the Droplet model for nuclei

Gray, T.J., see Hasan, A.T.

Greiner, W., see Kun, S.Yu.

Greiner, W., see Zhang, Q.-R.

Gridnev, K.A., Kartamyshev, M.P., Vaagen, J.S., Lukyanov, V.K. \& Anagnostatos, G.S., The role of linear alpha-cluster configuration for ${ }^{12} \mathrm{C}$

Gu, X.-Y., Ma, Z.-Q. \& Dong, S.-H., Exact solutions to the Dirac equation for a Coulomb potential in $D+1$ dimensions

Gu, X.-Y., see Dong, S.-H.

Guliyev, E., Yavaş, Ö. \& Sultansoy, S., Collective excitations of the ${ }^{154} \mathrm{Sm}$ nucleus at the FEL $\otimes L H C$ collider

Gupta, S., Singh, B.P., Sharma, M.K., Prasad, R., Musthafa, M.M. \& Bhardwaj, H.D., Measurement of recoil ranges in the ${ }^{12} \mathrm{C}+$ ${ }^{165} \mathrm{Ho}$ system below $7 \mathrm{MeVI}$ nucleon

Guptaroy, P., see De, B.

Guptaroy, P., see De, B.

Hasan, A.T. \& Gray, T.J., Experimental study of singleelectron-capture cross sections by low-energy $\mathrm{N}_{2}^{+}$and $\mathrm{N}^{+}$ions in $\mathrm{N}_{2}$ molecular gas

Hasegawa, A., see Nakano, M.

Hassan, M.Y.M., see Farag, M.Y.H.

Irfan, M., see Bari, W.

Jain, A.K., see Malik, S.S.

Jain, S.R., see Malik, S.S.

Kabir, H., see Sarker, D.R.

Kakavand, T. \& Singh, K.P., Lifetimes of levels in ${ }^{71} \mathrm{Ge}$

Kalantari, S.Z. \& Sohani, M., Effects of the side-path model on the muon total sticking coefficient and cycling rate in $D / T \mu C F$

Kartamyshev, M.P., see Gridnev, K.A.

Khan, M.M., see Bari, W.

Kim, Y.J. \& Cha, M.H., Coulombmodified eikonal model analysis of
E11(1) 55

E11(6) 567

E11(4) 273

E11(3) 221

E11(5) 359

E11(4) 335

E11(6) 483

E11(6) 501

E11(1) 45

E11(4) 289

E11(5) 387

E11(6) 567

E11(4) 321

E11(5) 425

E11(2) 131

E11(4) 303

E11(4) 303

E11(5) 403

E11(4) 347

E11(6) 463

E11(6) 539

E11(5) 359

E11(2) 131 refractive ${ }^{12} \mathrm{C}+{ }^{12} \mathrm{C}$ elastic scattering at $E_{\text {lab }}=240$ and $360 \mathrm{MeV}$

Kouno, H., see Nakano, M.

Krishan, K., see Banerjee, P.

Kukulin, V.I., Obukhovsky, I.T., Pomerantsev, V.N. \& Faessler, A., Two-component dressed-bag model for NN interaction: Deuteron structure and phase shifts up to $1 \mathrm{GeV}$

Kun, S.Yu., Vagov, A.V., Chadderton, L.T. \& Greiner, W., A new probe for coherent manybody dynamics: Nonergodic molecules in continuum

E11(4) 273

Leite, T.N., Teruya, N. \& Dias, H., Very narrow resonances in spherical proton emitting nuclei

E11(3) 211

E11(4) 321

E11(6) 491

E11(1) 1

Lukyanov, V.K., see Gridnev, K.A.

Ma, Z.-Q., see Dong, S.-H.

Ma, Z.-Q., see Dong, S.-H.

Ma, Z.-Q., see Gu, X.-Y.

Mabuza, B.R., Adam, R.M. \& Bakker, B.L.G., The effect of antisymmetrization in diquark models of baryons

Madani, J.H., Mass dependence of p-nucleus total reaction cross section and Gambhir-Patil nucleon density distribution

Makino, K.-I., see Nakano, M.

Malik, S.S., Jain, A.K. \& Jain, S.R., Eigenvalue spectrum for a single particle in a spheroidal cavity: A semiclassical approach

Mansour, H.M.M. \& Ramadan, Kh.A., Neutron matter properties using generalized Skyrme force

Mansour, H.M.M., see Ramadan, Kh.A.

Marranghello, G.F., Vasconcellos, C.A.Z., Dillig M. \& de Freitas Pacheco, J.A., A nuclear manybody theory at finite temperature applied to a protoneutron star

Matsuura, H., see Nakano, M.

Mikhailyuk, V.P., see Berezhnoy, Yu.A.

Miller, H.G., see Tegen, R.

Mohery, M. \& Abd-Allah, N.N., Systematic comparison of the experimental data with the Fritiof model in nucleus-nucleus inter-
E11(1) 35

E11(6) 475

E11(4) 321

E11(4) 303

E11(5) 445

E11(2) 143

E11(2) 83

E11(4) 321

E11(4) 281

E11(6) 573

E11(6) 469

E11(2) 155

E11(6) 483

E11(4) 335 
actions with light and heavy target nuclei in nuclear emulsion at $4.5 \mathrm{~A} \mathrm{GeV/c}$

E11(2) 161

Musthafa, M.M., see Gupta, S.

Nagasawa, T., see Nakano, M.

Nakano, M., Matsuura, H., Nagasawa, T., Makino, K.-I., Noda, N., Tuchitani, K., Sakamoto, K., Kouno, H. \& Hasegawa, A., Vertex corrections in the nuclear Schwinger-Dyson formalism

Noda, N., see Nakano, M.

Obukhovsky, I.T., see Kukulin, V.I.

Pantelides, S.T., A new theory of electromagnetic, weak and strong interactions

Pomerantsev, V.N., see Kukulin, V.I.

Prasad, R., see Gupta, S.

Rahman, Md.A., see Sarker, D.R.

Ramadan, Kh.A. \& Mansour, H.M.M., Nuclear matter properties using different sets of parameters in the Gogny interaction

Ramadan, Kh.A., see Mansour, H.M.M.

Robson, B.A., A generation model of the fundamental particles

Sahu, R., see Tripathy, K.C.

Sakamoto, K., see Nakano, M.

Sandulescu, A., see Stefanescu, E.

Sandulescu, A., see Stefanescu, E.

Sarker, D.R., Kabir, H., Rahman, Md.A. \& Sen Gupta, H.M., Generalized diffraction model study of intermediate energy protonnucleus scattering

Sen Gupta, H.M., see Sarker, D.R.

Sharma, M.K., see Gupta, S.

Singh, B.P., see Gupta, S.

Singh, K.P., see Kakavand, T.
E11(1) 45

E11(4) 321

E11(4) 321

E11(4) 321

E11(1) 1

E11(3) 177

E11(1) 1

E11(1) 45

E11(5) 403

E11(2) 143

E11(5) 445

E11(6) 555

E11(6) 531

E11(4) 321

E11(2) 119

E11(5) 379

E11(5) 403

E11(5) 403

E11(1) 45

E11(1) 45

E11(4) 347
Singh, K.P., see Kakavand, T.

E11(6) 463

Sohani, M., see Kalantari, S.Z.

E11(6) 539

Stefanescu, E. \& Sandulescu, A., Dynamics of a Fermi system in a blackbody radiation field

E11(5) 379

Stefanescu, E. \& Sandulescu, A., Microscopic coefficients for the quantum master equation of a Fermi system

E11(2) 119

Strobel, G.L., Baryon magnetic moments and spin dependent quark forces

E11(1) 71

Sultansoy, S., see Guliyev, E.

E11(6) 501

Takook, M.V., Negative norm states in de Sitter space and QFT without renormalization procedure

E11(6) 509

Tarikci, A., see Yildirim, S.

Tegen, R. \& Miller, H.G., Neutrino mass from beta decay of the free neutron

Teruya, N., see Leite, T.N.

Tripathy, K.C. \& Sahu, R., Collective bands in ${ }^{68} \mathrm{Se}$

E11(5) 369

E11(6) 573

E11(6) 469

E11(6) 531

Tuchitani, K., see Nakano, M.

E11(4) 321

Vaagen, J.S., see Gridnev, K.A.

E11(5) 359

Vagov, A.V., see Kun, S.Yu.

E11(4) 273

Vasconcellos, C.A.Z., see Marranghello, G.F.

E11(2) 83

Yavaş, Ö., see Guliyev, E.

E11(6) 501

Yildirim, S. \& Tarikci, A., Collisional damping of giant resonances with an optimized finite-range effective interaction

E11(5) 369

Zafar, M., see Bari, W.

E11(2) 131

Zettili, N. \& Boukahil, A., The nuclear Born-Oppenheimer method applied to nuclear collective motion

Zhang, Q.-R. \& Greiner, W., Direct interaction between baryons and the extension of the relativistic mean field theory for nuclear matter

E11(3) 221

Zhang, Q.-R., see Gao, C.-Y. 